\title{
Real-time sector scan study of the mitral valve prolapse syndrome
}

\author{
MICHAEL V. COHEN
}

From Division of Cardiology, Department of Medicine, Montefiore Hospital and Medical Center and the Albert Einstein College of Medicine, Bronx, New York, USA

SUMMARY Real-time two-dimensional sector scanning was used to analyse mitral valve motion in 4 normal subjects and 6 patients with previously diagnosed mitral valve prolapse syndromes. The normal mitral valve leaflets remain apposed for the duration of systole, and open abruptly with the onset of diastole. During diastole the leaflets are parallel to each other and only the distal ends tend to 'float' closed. Atrial contraction bows the anterior leaflet anteriorly which thus encroaches on the left ventricular outflow tract. The leaflet tips again 'float' closed, but the major portion of the leaflets are not closed until onset of the succeeding left ventricular isovolumic contraction. The abnormal redundant tissue of the ballooning mitral valve is seen as a prominent structure immediately behind the posterior leaflet at the beginning of systole. In one patient with the time-motion pattern of pansystolic prolapse this redundant tissue moved posteriorly in systole and appeared to merge with the left atrial wall. Of the remaining 5 patients, 4 with late systolic prolapse had characteristic movements of this abnormal tissue. With the beginning of systole the redundant tissue moved superiorly and slightly anteriorly into the left atrium. In mid-systole at the time of the diagnostic changes in the standard time-motion study, the abnormal mitral valve tissue moved posteriorly and inferiorly to a position adjacent to the left atrial wall, and then at end-systole moved anteriorly to a mid-atrial position. During diastole the redundant tissue again moved posteriorly, and then again anteriorly to assume its mid-atrial position at the start of the next cardiac cycle. Hence, in at least some patients, the primary abnormality in the mitral valve prolapse syndrome is the mitral valve and not the left ventricle. There is definite prolapse of mitral valve tissue into the left atrium in this syndrome, and the prolapse appears to persist throughout systole regardless of the diagnostic pattern recorded with standard time-motion echocardiography. Furthermore, the redundant mitral valve tissue is the source of several distinct echoes which all follow the outlined course, thus accounting for the multiple parallel systolic echoes often observed in patients with the mitral valve prolapse syndrome.

Since the original description of the mitral valve prolapse syndrome in 1963 (Barlow et al.) numerous reports have documented the auscultatory (Barlow, 1965; Kesteloot and Houte, 1965; Barlow and Bosman, 1966; Hancock and Cohn, 1966; Linhart and Taylor, 1966; Behar et al., 1967; Barlow et al., 1968; Bittar and Sosa, 1968; Leachman et al., 1969; Fontana et al., 1970; Jeresaty, 1973), echocardiographic (Shah and Gramiak, 1970; Dillon et al., 1971; Kerber et al., 1971; DeMaria et al., 1974; Cohen, 1976), and angiographic (Dinsmore et al., 1970; Kittredge et al., 1970; Jeresaty, 1971; Gooch, et al., 1972; Liedtke et al., 1973; Scampardonis

Received for publication 18 October 1977 et al., 1973; Gulotta et al., 1974; Spindola-Franco et al., 1974) features of this distinctive valvular lesion. However, analysis of motion of the mitral valve leaflets in this syndrome has been hampered by technical limitations. Standard one-dimensional time-motion echocardiography can analyse only posterior-anterior movement. Of the usual angiographic projections the left anterior oblique view of the left ventriculogram is thought to be most comparable with the echocardiographic cardiac crosssection (Teichholz et al., 1974). However, superimposition of structures and regurgitant jets of dye into the left atrium often make it difficult to analyse movements of the radiolucent leaflets. As shown by Ranganathan and colleagues (1973) the right 
anterior oblique projection of the left ventriculogram details movement of only the posterior leaflet's three scallops. Furthermore, this radiographic view does not allow accurate analysis of anterior-posterior motion.

Introduction of two-dimensional echocardiographic techniques has expanded our diagnostic ability, and has recently been used to investigate the mitral valve prolapse syndrome. B-scan ultrasonography displays gated, stop-action frames, but has been unable to detect prolapse of mitral leaflets into the left atrium (Millman et al., 1976). However, real-time multiple-crystal (Sahn et al., 1976) and phased array (Gilbert et al., 1976) cross-sectional echocardiographic studies have suggested that during systole mitral leaflets in the prolapse syndrome do arch superiorly into the atrium. The present report details use of a third two-dimensional echocardiographic technique. With the real-time sector scanner it has been possible to show dynamic motion of redundant mitral leaflets during all phases of the cardiac cycle. The scanner clearly depicts systolic prolapse into the left atrium, and suggests that multiple echoes may emanate from a single redundant leaflet.

\section{Methods}

All patients studied were referred to the noninvasive laboratory of Montefiore Hospital and Medical Center for diagnostic evaluation. Standard time-motion echocardiographic studies were performed with a Hoffrel Ultrasonoscope, Model 101, and either a $2.25 \mathrm{MHz}$ transducer focused at $7.5 \mathrm{~cm}$ or an unfocused $2.0 \mathrm{MHz}$ transducer. The patient was either supine or slightly rotated to the left to enable optimal echocardiographic examination. Echocardiographic information was displayed on a Cambridge multichannel oscillographic recorder and permanent photographic records obtained with a strip chart recorder. A simultaneous electrocardiographic lead II was also continuously recorded.

Six patients with echocardiograms showing the systolic deformity characteristic of the mitral valve prolapse syndrome underwent additional examination with a Hoffrel Mechanical Sector Scanner (also called Wobbler). This scanning echocardiograph uses a standard $2 \cdot 25 \mathrm{MHz}$ adult cardiac transducer mounted in a special scanning head so it can be oscillated rapidly back and forth over a sector of 35 degrees. The echo signals generated by the scanning system are displayed on a television screen at a rate of 30 frames per second and recorded by a synchronised video tape recorder for later playback and analysis. Selected still frames may be photographed from the television screen during playback with a $35 \mathrm{~mm}$ camera. Means are provided in the scanning system to determine accurately the time location of each scanning frame within the cardiac cycle. In the sector scanner used in this study concentric circles of light-emitting diodes provided timing information in tenths and hundredths of a second, with the timing information referenced to a trigger derived from the $R$ wave of the electrocardiogram.

Of the 6 patients studied, 4 were male ranging in age from 14 to 42 years (average 30.8 years). The 2 women were 47 and 51 years old. Two of the male patients and 1 woman had the clinical diagnosis of Marfan's syndrome. One of these was a 14-year-old boy, and the 47-year-old woman with normai body habitus was his mother. One patient had a straight back syndrome without any other apparent cardiac abnormality, and 2 patients had no skeletal or other cardiac lesions.

Standard time-motion and real-time sector scan echocardiograms were done in 4 normal male cardiology residents less than 34-years-old. None had any cardiac symptoms, and all physical examinations were normal.

\section{Results}

Routine echocardiographic examinations in the 4 control subjects were normal. A systolic frame from the sector scan of one of these subjects and a line drawing are presented in Fig. 1. The light emitting diodes in the lower left corner indicate that this frame was recorded $0.21 \mathrm{~s}$ after inscription of a lead II $\mathbf{R}$ wave. The anterior and posterior mitral leaflets are in a closed position, while the proximal aortic root is expanded because of the stroke volume which is being ejected. The left atrium is partially filled. Only the base of the left ventricle is visualised in this frame. Because of the $35^{\circ}$ arc it was not possible to record echoes from the mitral valve leaflets and the entire left ventricular silhouette in the same frame. Only portions of the interventricular septum and right ventricular cavity can be defined.

Five selected frames from one cardiac cycle of a sector scan study in a normal subject are shown in Fig. 2. These frames show the movements of the mitral leaflets in diastole and systole. Fig. 3 shows the time motion echocardigram of the same subject, and the arrows mark the approximate times at which the 5 sector scan frames were recorded. At the beginning of systole ( $0.09 \mathrm{~s}$ after $R$ wave inscription) the 2 mitral leaflets are in their closed position, and this position is maintained throughout systole $(0.4 \mathrm{~s})$. The systolic leaflet apposition is perhaps better appreciated in the frame recorded at approxi- 
Fig. 1 Photograph and artist's reproduction of a systolic frame of a real-time sector scan of a normal subject. The anterior $(A M L)$ and posterior $(P M L)$ mitral leaflets are apposed. The left atrium $(L A)$ and aortic $(A o)$ root are clearly seen, but only the base of the left $(L V)$ and right $(R V)$ ventricles is visualised because of the boundary imposed by the $35^{\circ}$ arc of the mechanically oscillated transducer. Ant, anterior; post, posterior.

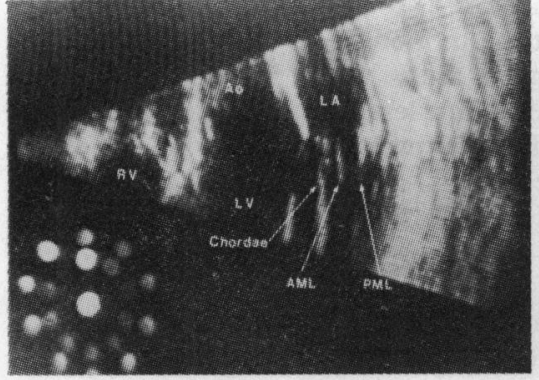

0.09 s early-systole

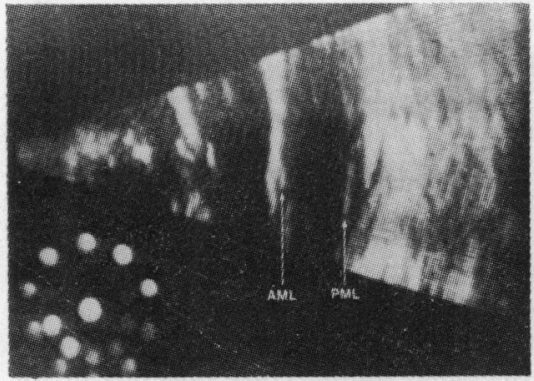

$0.72 \mathrm{~s}$ mid-diastole

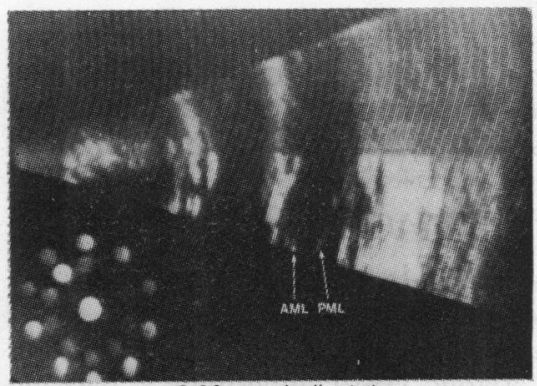

0.98 s end-diastole

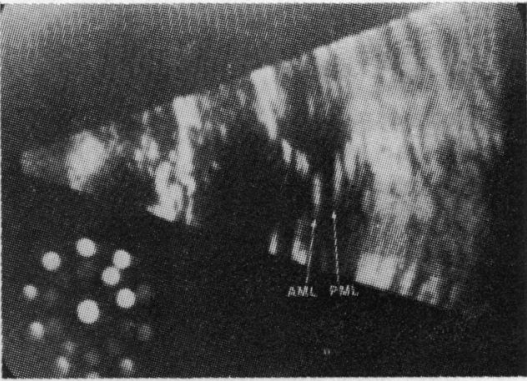

$0.21 \mathrm{~s}$ mid-systole

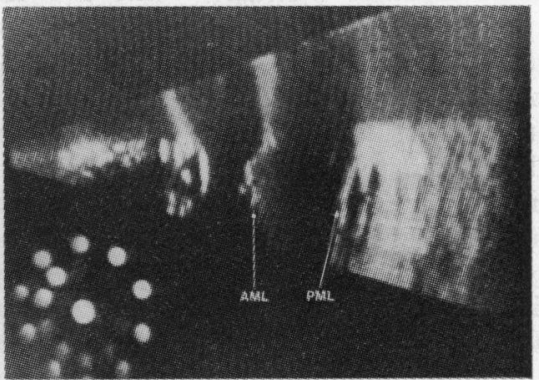

0.93 s late diastole
Fig. 2 Five sector scan frames from a normal subject showing the motion of the anterior $(A M L)$ and posterior (PML) mitral leaflets in systole and diastole. Times refer to the intervals following inscription of the $R$ wave. Abbreviations: see Fig. 1. 


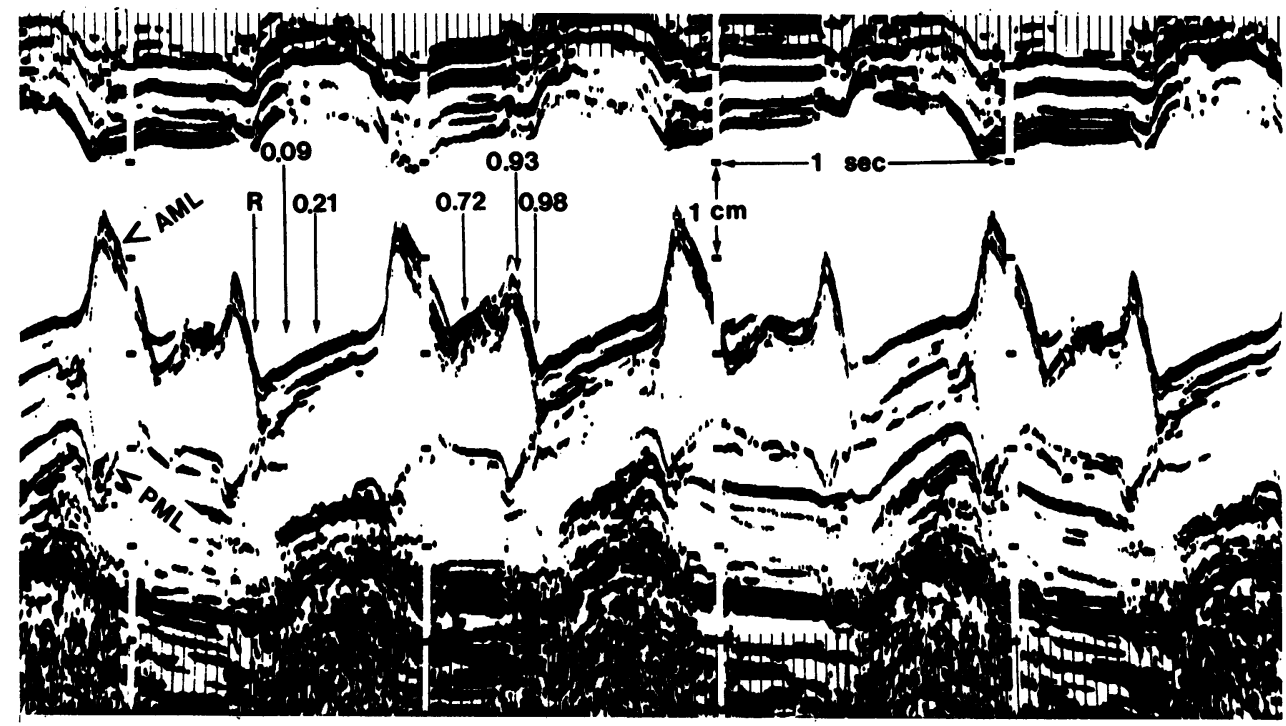

Fig. 3 Standard time motion echocardiogram of the mitral valve from the same subject whose sector scan is presented in Fig. 2. Arrows mark the intervals (s) after $R$ wave inscription at which the sector scan frames of Fig. 2 were recorded. Abbreviations: see Fig. 1.

mately $0 \cdot 21 \mathrm{~s}$ after the $\mathrm{R}$ wave. At the beginning of diastole the leaflets abruptly open and assume a parallel configuration. Even in mid-diastole $(0.72 \mathrm{~s})$ the leaflets are still parallel to each other, and only the most distal parts of the leaflets showed any tendency to float closed. The effect of a vigorously contracting left atrium is seen in the last two frames $(0.93$ and $0.98 \mathrm{~s})$. In the earlier frame, atrial contraction bows the body of the anterior leaflet anteriorly with consequent encroachment on the left ventricular outflow tract. A comparatively minor posterior movement of the posterior leaflet is also evident. In the last frame only the distal tips of the leaflets are seen to be floating towards each other, while the major distal portions of the leaflets remain parallel. With the start of the new cardiac cycle, isovolumic left ventricular contraction rapidly closes the mitral valve orifice.

Of the 6 patients with mitral valve prolapse syndrome studied by sector scanning, 5 had late systolic prolapse, and 1 had pansystolic prolapse. In the latter patient the prolapsing portion of the valve rapidly moved posteriorly and echoes from the leaflet tissue could not easily be distinguished from those from the left atrial wall. Of the 5 patients with late systolic prolapse, 4 had abnormal sector scans. Six representative frames from the scan of 1 of these patients are shown in Fig. 4, and the corresponding time-motion study is seen in Fig. 5. The first frame recorded $0.03 \mathrm{~s}$ after $R$ wave inscription (Fig. 4) shows apposition of the anterior and posterior mitral leaflets. Immediately posterior to the posterior leaflet is a thick, elongated structure which is thought to represent redundant mitral leaflet tissue. In no patient was a similar structure clearly associated with the anterior leaflet. During systole the anterior leaflet is visualised indistinctly, while the posterior leaflet cannot clearly be defined. However, the abnormal mitral valve tissue is clearly visualised, and is mobile. During early systole when the standard echocardiogram shows only minimal anterior excursion of the mitral leaflets, the abnormal leaflet tissue leaves its initial mid-valvular position and moves superiorly and slightly anteriorly. At this time the structure appears to be fragmented. By mid-systole $(0.24 \mathrm{~s})$ the redundant mitral tissue has reached its most superior position and now begins to move posteriorly simultaneously with the beginning of posterior sagging of the mitral leaflets seen on the M-mode echocardiogram (Fig. 5); $0.1 \mathrm{~s}$ later $(0.35 \mathrm{~s})$ when the mitral prolapse is clearly evident on the standard echocardiogram (Fig. 5) the structure has moved inferiorly and posteriorly, and is adjacent to the wall of an expanding left atrium. At end-systole $(0.42 \mathrm{~s})$ the abnormal leaflet tissue is again in a mid-valvular position. During early diastole $(0.61 \mathrm{~s})$ the apparently fragmented structure again moves posteriorly towards the left atrial wall. Slightly later in diastole $(0.77 \mathrm{~s})$ the fragmentation of the abnormal structure is especially 


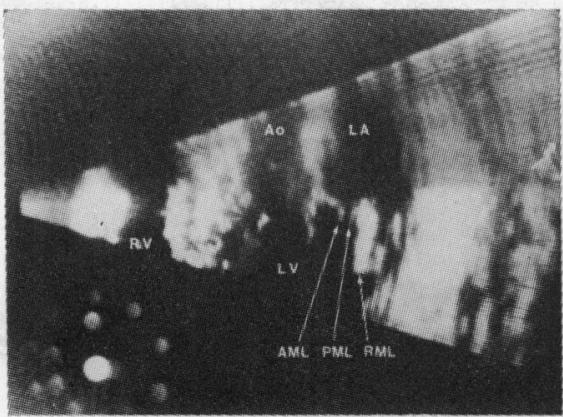

0.035 early-systole

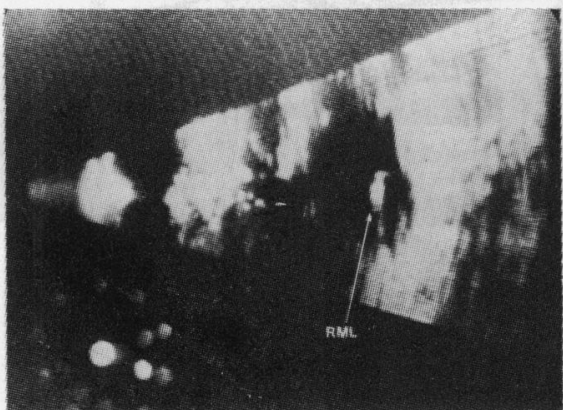

0.35 s late-systole

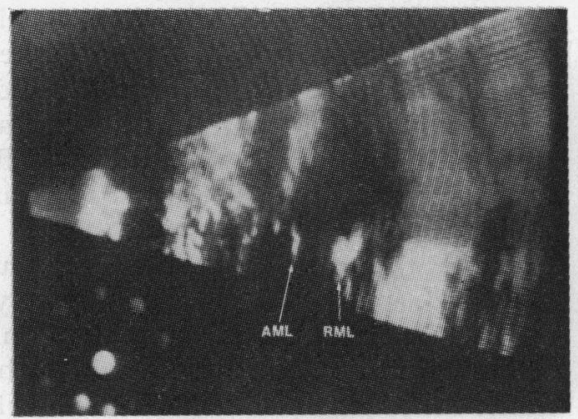

0.615 early-diastole

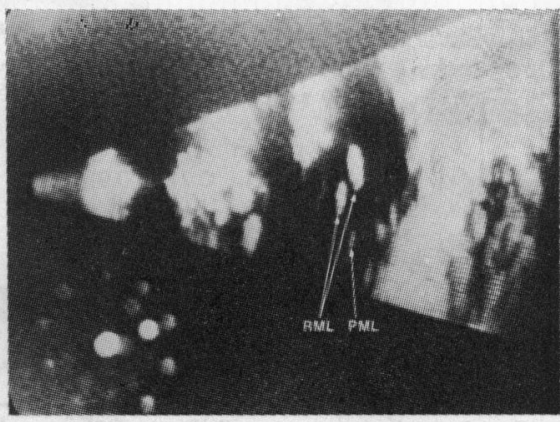

0.245 mid-systole

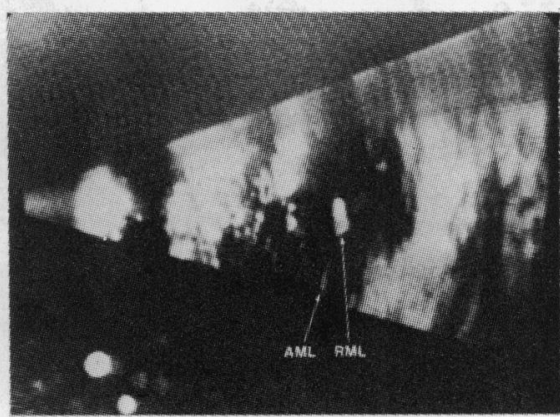

0.42 s end-systole

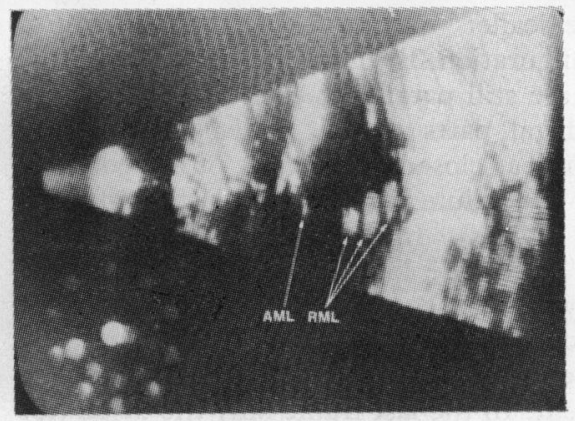

0.77 s late-diastole

Fig. 4 Six sector scan frames from a patient with previously diagnosed mitral valve prolapse syndrome. During systole the actual anterior (AML) and posterior (PML) mitral leaflets are not well seen, but the redundant mitral leaflet tissue $(R M L)$ can be seen initially to move superiorly and slightly anteriorly into the left atrium, then inferiorly and posteriorly, and finally anteriorly to a mid-valvular position at the end of systole. The abnormal mitral structure at times appears to be fragmented accounting for the multiple systolic echoes recorded on the standard time motion echocardiogram (Fig. 5). Times refer to the intervals after inscription of the $R$ wave. Abbreviations: see Fig. 1.

distinct. As the left atrial size diminishes there appears to be an anterior movement of the abnormal leaflet tissue.

Abnormal mitral valve structures were identified in 4 patients. The general pattern of superior, slightly anterior, and then inferior-posterior systolic motion was noted in all. In diastole resumption of a midvalvular position was apparent.

\section{Discussion}

Echocardiography is currently used to diagnose a 


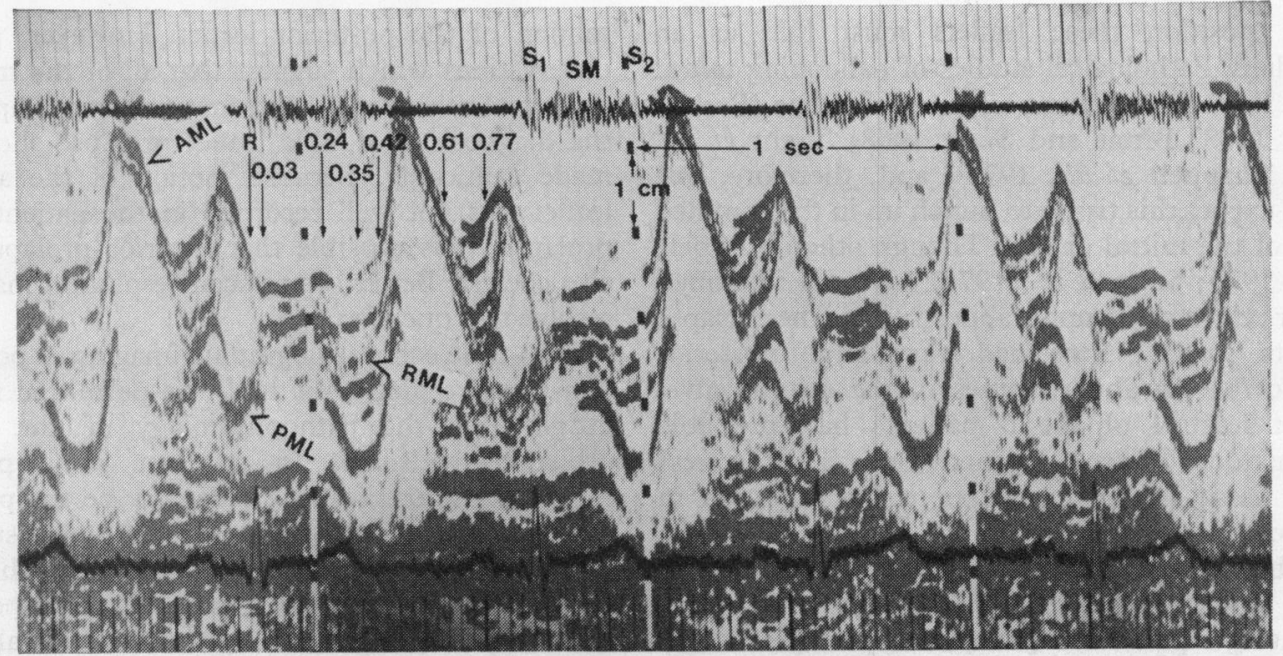

Fig. 5 Standard time motion echocardiogram of the mitral valve from the same subject whose sector scan is presented in Fig. 4. A mid-systolic prolapse pattern is evident. The multiple parallel systolic echoes probably represent reflection of sound waves from redundant mitral leaflet tissue (RML). Arrows mark the intervals $(s)$ after $R$ wave inscription at which the sector scan frames of Fig. 4 were recorded.

Abbreviations: see Fig. 1. SM, systolic murmur.

variety of adult and paediatric cardiac abnormalities. However, the standard time-motion presentation allows evaluation of structure movement in only an anterior-posterior plane. Furthermore, because movement of only one segment of a structure can be recorded at any given time, the echocardiographer must infer that this motion is representative of the whole. Newer two-dimensional and real-time scanning techniques seek to eliminate these objections. Scans allow evaluation of motion in simultaneous anterior-posterior and superior-inferior planes, and provide echo reception from large contiguous areas.

The sequence presented in Fig. 2 shows the movement of normal mitral leaflets during a cardiac cycle. During the entire systole the leaflets remain in a mid-valvular position sealing the mitral orifice, but open abruptly with the start of diastole. The sector scan shows gradual apposition of only the distal tips of the two leaflets during diastole. The major portions of the leaflets appear to close only with the onset of isovolumic contraction shortly after inscription of the $R$ wave. It seems that most of the valve tissue is affected by pressure and not volume changes within the left ventricle.

The mitral valve prolapse syndrome has recently been the subject of two-dimensional echocardiographic study (Gilbert et al., 1976; Millman et al., 1976; Sahn et al., 1976). B-scanning was unable to detect leaflet movement into the left atrium (Millman et al., 1976), and multiple crystal scans visualise only superior systolic arching of the leaflets (Gilbert et al., 1976; Sahn et al., 1976). Though the latter scans were able to detect abnormal systolic arching of the mitral leaflets in patients with prolapse, no posteriorly moving structure was visualised to account for the prominent systolic deformity seen on the TM-echocardiogram. Simple superior movements would not be detected by standard echocardiographic equipment. However, real-time sector scanning has now shown significant superior and posterior movements of redundant mitral leaflet tissue, and confirms mitral prolapse into the left atrium. Because this is a real-time technique, maximal appreciation of the described findings can be achieved only by viewing the videotape. Reproduction of single frames can, at most, provide a reasonable suggestion of the dynamic observations.

Correlation of the standard time motion (Fig. 5) and sector scan (Fig. 4) echocardiograms suggests that motion of the prominent structure immediately behind the central portion of the posterior mitral leaflet (Fig. 4) accounts for the late systolic deformity characteristic of mitral valve prolapse. This structure is felt to be redundant mitral leaflet tissue though this cannot be documented unequivocally. The single angiographic study in this group showed only posterior leaflet prolapse, and no patient has required valve replacement. The cross-sectional area of normal mitral leaflets is 1.5 to 2.2 times greater than the area of the orifice. Therefore, when in the 
closed position these leaflets must fold as an accordion. Pathological studies of ballooning mitral valves have shown great excesses of tissue (Barlow et al., 1968; Bittar and Sosa, 1968; Trent et al., 1970; Shappell et al., 1973), and, therefore, one would expect this tissue to bunch up in the confined space of the mitral orifice. Though others (Gilbert et al., 1976; Sahn et al., 1976) have not identified similar echocardiographic abnormalities the prolapse patients studied here had very large posterior systolic motion abnormalities of the mitral valve, and at least 4 of the 6 patients had probable myxomatous leaflet degeneration. Thus excess leaflet tissue is not an unexpected observation in this group.

With the onset of systole the redundant mitral tissue is sometimes propelled posteriorly, thus generating a pattern of pansystolic prolapse on the time-motion echocardiogram. More often the posterior motion may be delayed by an initial superior and slightly anterior movement. In the latter situation the standard echocardiogram (Fig. 5) would show only a late systolic prolapse. Regardless of the standard echocardiographic prolapse pattern in the patients studied, it is apparent that the mitral leaflet prolapses into the left atrium for the entire systolic phase of the cardiac cycle. It is not clear why the leaflet motion in some patients is initially superior and anterior, while in others it is posterior. A previous study has shown that both the pansystolic and late systolic prolapse patterns may occur in the same patient (Cohen, 1976). The appearance of a late systolic murmur in many patients with mitral valve prolapse does not diminish the impact of the above conclusions. As pointed out previously (Cohen, 1976) the murmur is generated by blood regurgitating across the mitral orifice into the left atrium. Because the surface area of the leaflets exceeds the size of the orifice, bulging of the leaflets may occur before they separate enough to allow reflux of blood. Thus, prolapse may occur earlier than recorded auscultatory abnormalities might suggest.

The standard echocardiogram of three mitral valve prolapse patients chosen for this study showed multiple systolic echoes with the typical late systolic deformity (Fig. 5). As shown in Fig. 4 the redundant mitral valve tissue at times appeared to be fragmented, with each portion reflecting sound waves. Thus the multiple systolic echoes observed may all originate from a single-the posterior-leaflet. The diagnosis of double mitral leaflet prolapse has been based on the assumption that the most anterior systolic echo with a posterior movement represented motion of the anterior leaflet, while the more posterior echo reflected motion of the posterior leaflet. However, present observations which suggest that all of the multiple abnormal echoes may be from one leaflet imply that the diagnosis of double leaflet prolapse should be made cautiously. Because motion of the anterior leaflet was not well recorded in the patients with prolapse, it is possible that anterior prolapse may also coexist. Better sector scan resolution may help resolve this question.

Real-time echocardiographic imaging, a powerful non-invasive diagnostic tool, has permitted further insight into the pathophysiology of the mitral prolapse syndrome. In at least some patients redundant mitral leaflet tissue may be the primary abnormality in this syndrome. As suggested by Jeresaty (1975) one need not assume that left ventricular contraction abnormalities are responsible for the prolapsing valve syndrome. Mitral valve tissue does prolapse into the left atrium, and in many instances does so for the duration of the systolic phase of the cardiac cycle regardless of the standard time-motion echocardiographic pattern.

I thank Mr Richard Lee of Hoffrel Instruments, Inc. for assistance in performance and photographic reproduction of the sector scan studies.

\section{References}

Barlow, J. B. (1965). Conjoint clinic on the clinical significance of late systolic murmurs and non-ejection systolic clicks. Fournal of Chronic Diseases, 18, 665-673.

Barlow, J. B., and Bosman, C. K. (1966). Aneurysmal protrusion of the posterior leaflet of the mitral valve: an auscultatory-electrocardiographic syndrome. American Heart fournal, 71, 166-178.

Barlow, J. B., Bosman, C. K., Pocock, W. A., and Marchand, P. (1968). Late systolic murmurs and non-ejection ('midlate') systolic clicks: an analysis of 90 patients. British Heart fournal, 30, 203-218.

Barlow, J. B., Pocock, W. A., Marchand, P., and Denny, M. (1963). The significance of late systolic murmurs. American Heart fournal, 66, 443-452.

Behar, V. S., Whalen, R. E., and McIntosh, H. D. (1967). The ballooning mitral valve in patients with the 'precordial honk' or 'whoop'. American fournal of Cardiolog.v, 20, 789-795.

Bittar, N., and Sosa, J. A. (1968). The billowing mitral valve leaflet: report on fourteen patients. Circulation, 38, 763-770.

Cohen, M. V. (1976). Double mitral leaflet prolapse: echocardiographic-phonocardiographic correlation. American Heart fournal, 91, 168-177.

DeMaria, A. N., King, J. F., Bogren, H. G., Lies, J. E., and Mason, D. T. (1974). The variable spectrum of echocardiographic manifestations of the mitral valve prolapse syndrome. Circulation, 50, 33-41.

Dillon, J. C., Haine, C. L., Chang, S., and Feigenbaum, H. (1971). Use of echocardiography in patients with prolapsed mitral valve. Circulation, 43, 503-507.

Dinsmore, R. E., Hutter, A. M., Jr.. and Sanders, C. A. (1970). Angiographic and clinical spectrum of mitral valve prolapse (abstract). Circulation, 41 and 42, Suppl. III, 149. Fontana, M. E., Pence, H. L., Leighton, R. F., and Wooley 
C. F. (1970). The varying clinical spectrum of the systolic click-late systolic murmur syndrome: a postural auscultatory phenomenon. Circulation, 41, 807-816.

Gilbert, B. W., Schatz, R. A., VonRamm, O. T., Behar, V. S., and Kisslo, J. A. (1976). Mitral valve prolapse: two-dimensional echocardiographic and angiographic correlation. Circulation, 54, 716-723.

Gooch, A. S., Vicencio, F., Maranhao, V., and Goldberg, H. (1972). Arrhythmias and left ventricular asynergy in the prolapsing mitral leaflet syndrome. American fournal of Cardiology, 29, 611-620.

Gulotta, S. J., Gulco, L., Padmanabhan, V., and Miller, S. (1974). The syndrome of systolic click, murmur, and mitral valve prolapse-a cardiomyopathy? Circulation, 49, 717-728.

Hancock, E. W., and Cohn, K. (1966). The syndrome associated with midsystolic click and late systolic murmur. American fournal of Medicine, 41, 183-196.

Jeresaty, R. M. (1971). Ballooning of the mitral valve leaflets: angiographic study of 24 patients. Radiology, 100, 45-52.

Jeresaty, R. M. (1973). Mitral valve prolapse-click syndrome. Progress in Cardiovascular Diseases, 15, 623-652.

Jeresaty, R. M. (1975). Etiology of the mitral valve prolapseclick syndrome. American fournal of Cardiology, 36, 110-113.

Kerber, R. E., Isaeff, D. M., and Hancock, E. W. (1971). Echocardiographic patterns in patients with the syndrome of systolic click and late systolic murmur. New England Fournal of Medicine, 284, 691-693.

Kesteloot, H., and Houte, O. van (1965). On the origin of the telesystolic murmur preceded by a click. Acta Cardiologia, 20, 197-209.

Kittredge, R. D., Shimomura, S., Cameron, A., and Bell, A. L. L., Jr. (1970). Prolapsing mitral valve leaflets: cineangiographic demonstration. American fournal of Roentgenology, Radium Therapy and Nuclear Medicine, 109, 84-93.

Leachman, R. D., De Francheschi, A., and Zamalloa, O. (1969). Late systolic murmurs and clicks associated with abnormal mitral valve ring. American fournal of Cardiology, 23, 679-683.

Liedtke, A. J., Gault, J. H., Leaman, D. M., and Blumenthal, M. S. (1973). Geometry of left ventricular contraction in the systolic click syndrome: characterization of a segmental myocardial abnormality. Circulation, 47, 27-35.

Linhart, J. W., and Taylor, W. J. (1966). The late apical systolic murmur: clinical, hemodynamic and angiographic observations. American fournal of Cardiology, 18, 164-168.

Millman, A. E., Meller, J., Herman, M. V., and Teichholz, L. E. (1976). Dynamic B-scan ultrasonography in the study of mitral valve prolapse (abstract). American fournal of Cardiology, 37, 156.

Ranganathan, N., Silver, M. D., Robinson, T. I., Kostuk, W. J., Felderhof, C. H., Patt, N. L., Wilson, J. K., and Wigle, E. D. (1973). Angiographic-morphologic correlation in patients with severe mitral regurgitation due to prolapse of the posterior mitral valve leaflet. Circulation, 48, 514-518.

Sahn, D. J., Allen, H. D., Goldberg, S. J., and Friedman, W. F. (1976). Mitral valve prolapse in children: a problem defined by real-time cross-sectional echocardiography. Circulation, 53, 651-657.

Scampardonis, G., Yang, S. S., Maranhao, V., Goldberg, H., and Gooch, A. S. (1973). Left ventricular abnormalities in prolapsed mitral leaflet syndrome: review of eighty-seven cases. Circulation, 48, 287-297.

Shah, P. M., and Gramiak, R. (1970). Echocardiographic recognition of mitral valve prolapse (abstract). Circulation, 41 and 42, Suppl. III, 45.

Shappell, S. D., Marshall, C. E., Brown, R. E., and Bruce, T. A. (1973). Sudden death and the familial occurrence of mid-systolic click, late systolic murmur syndrome. Circulation, 48, 1128-1134.

Spindola-Franco, H., Bjork, L., Miller, S., and Adams, D. F. (1974). Prolapse of the mitral valve: analysis of variations of the normal mitral apparatus and a description of two new angiocardiographic signs (abstract). Circulation, 49 and 50, Suppl. III, 207.

Teichholz, L. E., Cohen, M. V., Sonnenblick, E. H., and Gorlin, R. (1974). Study of left ventricular geometry and function by B-scan ultrasonography in patients with and without asynergy. New England fournal of Medicine, 291, 1220-1226.

Trent, J. K., Adelman, A. G., Wigle, E. D., and Silver, M. D. (1970). Morphology of a prolapsed posterior mitral valve leaflet. American Heart fournal, 79, 539-543.

Requests for reprints to Dr Michael V. Cohen, Division of Cardiology, Montefiore Hospital and Medical Center, 111 East 210 Street, Bronx, New York 10467, USA. 